\title{
Pilot safety study of intrabronchial instillation of bone marrow-derived mononuclear cells in patients with silicosis
}

\author{
Marcelo M. Morales ${ }^{1 *}$, Sérgio A. L. Souza², Luiz Paulo Loivos³, Marina A. Lima ${ }^{3}$, Amir Szklo ${ }^{3}$, Leandro Vairo ${ }^{4}$, \\ Taís H. K. Brunswick', Bianca Gutfilen², Miquéias Lopes-Pacheco ${ }^{1,5}$, Alberto J. Araújo ${ }^{3}$, Alexandre P. Cardoso ${ }^{3}$, \\ Regina C. Goldenberg ${ }^{4}$, Patricia R. M. Rocco ${ }^{5}$, Lea M. B. Fonseca² and José R. Lapa e Silva ${ }^{3}$
}

\begin{abstract}
Background: Silicosis is an occupational disease for which no effective treatment is currently known. Systemic administration of bone marrow-derived mononuclear cells (BMDMCs) has shown to be safe in lung diseases. However, so far, no studies have analyzed whether bronchoscopic instillation of autologous BMDMCs is a safe route of administration in patients with silicosis.
\end{abstract}

Methods: We conducted a prospective, non-randomized, single-center longitudinal study in five patients. Inclusion criteria were age 18-50 years, chronic and accelerated silicosis, forced expiratory volume in $1 \mathrm{~s}<60 \%$ and $>40 \%$, forced vital capacity $\geq 60 \%$ and arterial oxygen saturation $>90 \%$. The exclusion criteria were smoking, active tuberculosis, neoplasms, autoimmune disorders, heart, liver or renal diseases, or inability to undergo bronchoscopy. BMDMCs were administered through bronchoscopy $\left(2 \times 10^{7}\right.$ cells) into both lungs. Physical examination, laboratory evaluations, quality of life questionnaires, computed tomography of the chest, lung function tests, and perfusion scans were performed before the start of treatment and up to 360 days after BMDMC therapy. Additionally, whole-body and planar scans were evaluated 2 and $24 \mathrm{~h}$ after instillation.

Results: No adverse events were observed during and after BMDMC administration. Lung function, quality of life and radiologic features remained stable throughout follow-up. Furthermore, an early increase of perfusion in the base of both lungs was observed and sustained after BMDMC administration.

Conclusion: Administration of BMDMCs through bronchoscopy appears to be feasible and safe in accelerated and chronic silicosis. This pilot study provides a basis for prospective randomized trials to assess the efficacy of this treatment approach.

Clinical trials.gov identifier: NCT01239862 Date of Registration: November 10, 2010

Keywords: Pneumoconiosis, Chronic inflammation, Lung fibrosis, Cell therapy

\section{Background}

Silicosis is a pneumoconiosis caused by inhalation of crystalline silica particles. Deposition of these particles in the lung tissue leads to a chronic inflammatory process with formation of silicotic nodules and collagen

\footnotetext{
*Correspondence: mmorales@biof.ufrj.br

'Laboratory of Cellular and Molecular Physiology, Institute of Biophysics Carlos Chagas Filho, da Saude Science Center, Federal University of Rio de Janeiro, Ilha do Fundão, 21941-902 Rio de Janeiro, RJ, Brazil

Full list of author information is available at the end of the article
}

deposition $[1,2]$. To date, there has been no effective therapy to minimize the progression of silicosis [3].

Bone marrow derived-mononuclear cells (BMDMCs) have exhibited beneficial effects for the treatment of various diseases due to their multipotent effects [4]. They are easily obtained for autologous transplantation and can be used on the same day of harvesting at a low cost and without risk of cell rejection (graft-versus-host disease) [5]. Additionally, a preclinical study from our group showed that intratracheal instillation of BMDMCs 
improved lung mechanics and reduced fibrosis in murine silicosis [6-8].

Based on the foregoing, we tested the hypothesis that intrabronchial instillation through bronchoscopy of autologous BMDMCs in individuals with accelerated and chronic silicosis would be feasible and safe.

\section{Methods}

A prospective, non-randomized, single-center longitudinal study was conducted to evaluate the feasibility and safety of intrabronchial instillation of BMDMCs in patients with accelerated and chronic silicosis. Patients were referred to the Clementino Fraga Filho University Hospital (HUCFF), Federal University of Rio de Janeiro (UFRJ), Brazil, from other institutions. All patients were investigated and treated according to the Occupational Lung Diseases Guidelines for Silicosis of the Brazilian Respiratory Society [9]. The diagnosis of silicosis was established by history of occupational exposure to silica crystals, presence of respiratory symptoms such as shortness of breath and cough, and radiologic abnormalities (bilateral nodular infiltrates with coalescence). The radiographic changes were read and confirmed by at least two independent radiologists. Informed consent was obtained from each patient and the study protocol was approved by the Brazilian National Ethical and Research Committee/CONEP (study ID number: CONEP5772008) and registered at ClinicalTrials.gov (identifier: NCT01239862). In addition to intrabronchial autologous infusion of BMDMCs, the patients received standard care according to the institutional protocol of the Pulmonary Division/HUCFF/UFRJ; however, no patients were treated with inhaled or systemic corticosteroids.

\section{Study population}

Forty-one patients with silicosis were screened for eligibility. All but one were male. The reasons for exclusion were normal spirometry $(n=19)$, spirometry parameters outside the study range $(n=5)$, death during screening $(\mathrm{n}=3)$, loss to follow-up during screening $(\mathrm{n}=3)$, refusal to sign informed consent $(\mathrm{n}=3)$, active tuberculosis found at screening $(\mathrm{n}=1)$, patient outside age range $(\mathrm{n}=1)$, and psychiatric disorder $(\mathrm{n}=1)$. Five males were included in the study, with a mean age at intervention of 41 years (range $37-45$ years). Patients met the following inclusion criteria: (1) age between 18 and 50 years; (2) chronic or accelerated silicosis characterized by the presence of new areas of fibrosis in high-resolution computed tomography of the lungs in the last 2 years; (3) pulmonary function tests showing moderate to severe impairment, characterized by forced expiratory volume in $1 \mathrm{~s}\left(\mathrm{FEV}_{1}\right)<60 \%$ predicted and $>40 \%$ predicted, and forced vital capacity (FVC) $\geq 60 \%$ predicted but with arterial oxygen saturation $>90 \%$ on room air. Patients were excluded if they met any of the following criteria: (1) unable to undergo bronchoscopy for instillation of cellular material, (2) infectious diseases at the time of the study or 1 month before enrollment, (3) other lung diseases, including active tuberculosis, (4) current or recent smoker, within 12 months of inclusion, characterized by tobacco intake $>10$ pack-years, (5) intra- or extrathoracic malignant neoplasms, (6) autoimmune disorders, (7) acute or unstable heart failure, (8) acute or uncontrolled coronary insufficiency, (9) primary hematologic disorders, (10) osteopathy reflecting increased risk for bone marrow aspiration, (11) primary or secondary coagulopathies, (12) liver failure, (13) moderate renal failure (creatinine level $>2 \mathrm{mg} / \mathrm{dL}$ ), (14) dependence on respiratory or circulatory support, (15) pregnancy, (16) human immunodeficiency virus seropositivity, and (17) participation in other clinical trials. The primary endpoint focused on safety and included death and respiratory (clinical, radiologic and functional) deterioration.

\section{Bone marrow aspiration, cell separation and intrabronchial instillation}

Bone marrow aspiration and subsequent cell preparation were accomplished on the same day as the infusion of intrabronchial autologous BMDMCs, and lasted 2-4 h. Collection was performed under local anesthesia and light sedation, through puncture and repeated aspirations at the posterior iliac crest region. A total of $80 \mathrm{~mL}$ of bone marrow aspirate was collected from each patient, and after removal of bone and fatty residues, mononuclear cells were isolated by a Ficoll-Paque Plus (Amersham Biosciences, São Paulo, Brazil) density gradient, washed three times in saline solution, resuspended in saline with $5 \%$ human albumin, and filtered through a $100-\mu \mathrm{m}$ nylon filter. After washing, counting, and viability testing, the cells were resuspended in $10 \mathrm{ml}$ saline solution with $5 \%$ autologous serum, and $2 \times 10^{7}$ cells were labeled with $99 \mathrm{mTc}$, as described in previously published protocols $[10,11]$. In brief, $500 \mu \mathrm{l}$ of sterile $\mathrm{SnCl}_{2}$ solution was added to the cell suspension in $0.9 \%$ $\mathrm{NaCl}$, and the mixture was incubated for $10 \mathrm{~min}$ at room temperature. Then, $45 \mathrm{mCi} 99 \mathrm{mTc}$ was added and incubation was continued for $10 \mathrm{~min}$. After centrifugation ( $500 \times \mathrm{g}$ for $5 \mathrm{~min}$ ), the supernatant was removed, the cells were washed again in saline solution, and the pellet was resuspended in saline solution. All cell preparation and labeling procedures were performed in a laminar flow hood. Bacteriological analyses and cultures were also carried out to exclude contamination of the material. A sample of the isolated BMDMCs was characterized by flow-cytometry analysis of specific surface antigens as previously described [11]. The viability of labeled cells was assessed by the trypan blue exclusion test, and was estimated to be greater than $90 \%$ in all cases. A 50-mL aliquot of the autologous 
BMDMC solution was instilled into each lung and distributed through the lobes by a fiber optic bronchoscope over a 30-min period. Following instillation, patients were positioned in left and right lateral decubitus and Trendelenburg position to facilitate dispersion of the instilled cells. After the procedure, patients were monitored for $1 \mathrm{~h}$ and sent to the Nuclear Medicine Department for examinations.

\section{Flow-cytometry analysis}

Isolated BMDMCs were characterized by flow-cytometry analysis of specific surface antigens. Cells were incubated for $20 \mathrm{~min}$ at room temperature with primary antibodies conjugated with fluorescein isothiocyanate (FITC), phycoerythrin (PE), allophycocyanin (APC), peridinin-chlorophyll-protein (PercP), and phycoerythrin/cyanine 7 ( $\mathrm{PE} / \mathrm{Cy} 7)$. The markers tested included: pan-leukocyte, CD45 (Immunostep); pan T cell, CD3 (BD Biosciences Pharmingen); cytotoxic T cell, CD8 (BD Biosciences Pharmingen); helper T cell, CD4 (BD Biosciences Pharmingen); pan B cell, CD19 (BD Biosciences Pharmingen); NK cell, CD56 (BD Biosciences Pharmingen); promonocyte, CD64 (Immunotech); monocyte, CD14 (IQP); hematopoietic progenitor cells, CD117 (BD Biosciences Pharmingen) and CD34 (BD Biosciences Pharmingen); mesenchymal cells, CD105 (Immunostep), CD73 (BD Biosciences Pharmingen), and CD90 (BD Biosciences Pharmingen); neutrophils, CD31 (BD Biosciences Pharmingen) and CD33 (BD Biosciences Pharmingen); and anti-HLA-DR (MHC-II, BD Biosciences Pharmingen). After staining, erythrocytes were lysed with B\&D Lysis Buffer Solution. Data were acquired on a BD FACS CANTO cytometer (BD Biosciences) and analyzed with BD Paint-a-Gate software.

\section{Measured variables}

Patient demographics, medical history, vital signs, routine laboratory tests (blood counts, coagulation tests, biochemical measurements, liver function tests), electrocardiogram, the Saint George Respiratory Questionnaire (SGRQ), the SF-36 Quality of Life Questionnaire, the Modified Borg Dyspnea Scale and the 6-min walk test were assessed using standardized clinical report forms before BMDMC administration (baseline) and at 1, 3, 7, $30,60,90,180,360$ days after the procedure. Lung function tests, including diffusing capacity of lung for carbon monoxide (DLCO) and arterial blood gases, lung CT scans, and lung perfusion scintigraphy were performed at baseline, up to 7 days, and 30, 60, 90, 180 and 360 days after cell transplantation.

\section{Instillation procedure and imaging analysis}

After bone marrow harvesting, approximately $2 \times 10^{7}$ BMDMCs were labeled with technetium-99 m (99mTc) and instilled in the bronchi through fiber optic bronchoscopy. Whole-body, planar and tomographic scintigraphy was carried out at $2 \mathrm{~h}$ and $24 \mathrm{~h}$ after cell transplantation. All cell preparation and labeling procedures were performed in a laminar flow. Briefly, $500 \mu \mathrm{L}$ of sterile $\mathrm{SnCl}_{2}$ solution was added to the cells and the mixture was incubated at room temperature for $10 \mathrm{~min} ; 45 \mathrm{mCi}$ of $99 \mathrm{mTc}$ was then added and incubation continued for another $10 \mathrm{~min}$. After centrifugation $(500 \times g$ for $5 \mathrm{~min}$ ), the supernatant was removed and the cells were washed in saline solution. The pellet was also resuspended in saline solution. Viability of the labeled cells was assessed by the Trypan Blue exclusion test, and was estimated to be greater than $93 \%$ in all cases. Labeling efficiency (\%) was calculated by the activity in the pellet divided by the sum of the radioactivity in the pellet plus supernatant and was estimated to be greater than $90 \%$ in all cases. Perfusion scintigraphy with $99 \mathrm{mTc}-$ MAA (Tc-99 m macroaggregated albumin) was performed before and 30, 60, 120, 180 and 360 days after BMDMC therapy. For regional analysis in both the anterior (A) and posterior $(\mathrm{P})$ images, rectangular regions of interest, equal in size, were drawn over the whole lung (A-whole lung and P-whole lung). Both lungs were divided into six regions of interest: right upper, right middle, right lower, left upper, left middle, and left lower lung fields. Regional blood flow evaluated by $99 \mathrm{mTc}$-MAA perfusion scintigraphy in each region of interest was calculated as per Ohno et al. [12]: $\mathrm{Q}_{\mathrm{PS}}(\%)=\left[\left(\mathrm{A}_{\text {roi }}+\mathrm{P}_{\mathrm{roi}} / 2\right) /\left(\mathrm{A}_{\text {whole lung }}+\right.\right.$ $\left.\left.\mathrm{P}_{\text {whole lung }} 2\right)\right] \times 100$, where $\mathrm{Q}_{\mathrm{PS}}$ is quantitative perfusion scintigraphy, $A_{\text {roi }}$ is the anterior region of interest, $P_{\text {roi }}$ is the posterior region of interest, $A_{\text {whole lung }}$ is the anterior whole lung, and $\mathrm{P}_{\text {whole lung }}$ is the posterior whole lung.

\section{Statistical analysis}

The Kolmogorov-Smirnov test with Lilliefors' correction was used to test for normality of data distribution; the Levene median test was used to evaluate the homogeneity of variances. The time course of functional data was evaluated using analysis of variance (ANOVA) followed by Tukey's test. Differences in quality of life and percentage of perfusion over time were assessed by repeated measures ANOVA on ranks followed by Tukey's post hoc test. The single imputation method of regression substitution for missing data of two patients at one time point in lung function analysis at 360 days was used. Nonparametric data were analyzed using repeated measures ANOVA on ranks followed by Tukey's post hoc test. Parametric data are expressed as means \pm standard error of the mean; nonparametric data are expressed as the median (interquartile range). The SigmaStat 3.1 statistical software package (Jandel Corporation, San Rafael, CA, USA) was used. A $p$-value $<0.05$ was considered significant. 


\section{Results}

Five patients were included in the study and followed up for 1 year after intrabronchial instillation of autologous BMDMCs. Table 1 presents the patients' characteristics at entry. All were men, had a mean age at intervention of 41 years (range 37-45 years) and a mean of 10 years (range 3-13 years) of dyspnea on exertion, and were nonsmokers or former-smokers. Exposure to silica was the result of sandblasting $(\mathrm{n}=3)$, quarry truck driving $(\mathrm{n}=1)$, and stone carving $(\mathrm{n}=1)$. Three had a history of tuberculosis treatment in the past, with no activity or sequelae at the time of the study. Lung function findings included a mean post-bronchodilator $\mathrm{FEV}_{1}$ of $58.6 \%$ (range, 48.3-64.1\%) and FVC of $87.9 \%$ (61.9-100.1\%), denoting airflow obstruction. The main finding on $\mathrm{CT}$ scans was disseminated small nodules and traction bronchiectasis. Sequential CT scans were performed until D360 in all participants, and no major changes were noted compared to the pre-intervention images.

Bronchoscopy and administration of BMDMCs were well tolerated. Two patients experienced mild wheezing after the infusion, which resolved quickly with bronchodilator nebulization. No immediate respiratory, cardiovascular, or hematological complications or other adverse events were observed throughout the 1-year follow-up.
Table 2 describes the progression of respiratory function during the study. After the first month, $\mathrm{FEV}_{1}$ improved in the first patient, with no further changes in other patients. Figure 1 illustrates the progression of quality of life domains during the follow-up period, as measured by the SF-36 questionnaire. These parameters remained stable throughout the observation period.

Imaging findings are shown in Figs. 2, 3 and 4. Figure 2a is a representative image of the heterogeneous distribution of the labeled cells in both lungs $2 \mathrm{~h}$ after instillation, with some uptake in the mouth and stomach due to swallowing of the instilled cells during bronchoscopy. Cells were identified in the lungs $24 \mathrm{~h}$ after instillation, with a similar distribution as at the 2-h time point (Fig. 2b). Figure 3 illustrates that cells were located mainly at sites exhibiting advanced fibrotic damage in the lungs.

Follow-up lung perfusion findings are illustrated in Fig. 4. Statistical analysis demonstrated that percent perfusion at the apex of the right and left lungs did not differ during the study period. In the middle third, percent perfusion was increased at day 30 in the right lung, whereas in the left lung it was higher at day 60 and remained unaltered at days 120, 180, and 360. In the base of the right lung, percent perfusion was higher at days $60,120,180$, and 360 compared with baseline, whereas a significant

Table 1 Demographic and clinical characteristics of the participants

\begin{tabular}{|c|c|c|c|c|c|}
\hline & Patient 1 & Patient 2 & Patient 3 & Patient 4 & Patient 5 \\
\hline $\begin{array}{l}\text { Age at intervention } \\
\text { (years) }\end{array}$ & 43 & 37 & 43 & 45 & 37 \\
\hline Sex & Male & Male & Male & Male & Male \\
\hline Race & White & White & White & White & Black \\
\hline Exposure & Stone carver & Sandblaster & $\begin{array}{l}\text { Stone quarry truck } \\
\text { driver }\end{array}$ & Sandblaster & Sandblaster \\
\hline $\begin{array}{l}\text { Duration of } \\
\text { symptoms (years) }\end{array}$ & 13 & 5 & 3 & 11 & 10 \\
\hline Main symptom & Dyspnea on exertion & $\begin{array}{l}\text { Progressive } \\
\text { dyspnea }\end{array}$ & Dyspnea on exertion & $\begin{array}{l}\text { Dyspnea on } \\
\text { exertion }\end{array}$ & $\begin{array}{l}\text { Dyspnea on } \\
\text { exertion }\end{array}$ \\
\hline $\begin{array}{l}\text { Other lung } \\
\text { diseases }\end{array}$ & No & $\begin{array}{l}\text { Tuberculosis in } \\
2004\end{array}$ & Tuberculosis in 1999 & Pneumonia in 2005 & $\begin{array}{l}\text { Tuberculosis in } \\
2002\end{array}$ \\
\hline Smoking & No & $\begin{array}{l}0.6 \text { pack-years, } \\
\text { stopped in } 2004\end{array}$ & $\begin{array}{l}8 \text { pack-years, stopped } \\
\text { in } 1999\end{array}$ & No & No \\
\hline Post-BD FEV ${ }_{1}(\%)$ & 55.7 & 48.3 & 62.1 & 64.6 & 62.9 \\
\hline Post-BD FVC (\%) & 89.3 & 61.9 & 94.7 & 100.1 & 93.7 \\
\hline $\begin{array}{l}\text { Main CT findings } \\
\text { at admission }\end{array}$ & $\begin{array}{l}\text { Irregular opacities, mainly at } \\
\text { the UULL, with traction bronchiectasis }\end{array}$ & $\begin{array}{l}\text { Diffuse reticulo- } \\
\text { nodular infiltrate }\end{array}$ & $\begin{array}{l}\text { Disseminated small } \\
\text { nodules, traction } \\
\text { bronchiectasis }\end{array}$ & $\begin{array}{l}\text { Disseminated small } \\
\text { nodules, traction } \\
\text { bronchiectasis }\end{array}$ & $\begin{array}{l}\text { Disseminated smal } \\
\text { nodules, traction } \\
\text { bronchiectasis }\end{array}$ \\
\hline Date of infusion & 8 Aug 2009 & 27 Aug 2009 & 3 Sep 2009 & 26 Oct 2012 & 4 Feb 2010 \\
\hline $\begin{array}{l}\text { Last outpatient } \\
\text { visit and status }\end{array}$ & 3 Mar 2015, stable & 3 Dec 2014, stable & 3 Dec 2012, stable & 22 Nov 2014, stable & $\begin{array}{l}22 \text { Aug 2011, active } \\
\text { TB }^{\mathrm{a}}\end{array}$ \\
\hline
\end{tabular}


Table 2 Functional parameters

\begin{tabular}{lllllll}
\hline & Day 0 & Day 7 & Day 30 & Day 60 & Day 180 & Day 360 \\
\hline FVC (\%) & $88.0 \pm 15.1$ & $86.3 \pm 15.5$ & $87.0 \pm 17.2$ & $86.1 \pm 14.1$ & $83.8 \pm 14.5$ & $88.0 \pm 22.8$ \\
FEV $1 \%$ (\%) & $58.7 \pm 6.7$ & $56.9 \pm 5.4$ & $57.9 \pm 5.6$ & $57.6 \pm 4.8$ & $55.6 \pm 6.6$ & $55.5 \pm 7.2$ \\
TLC (\%) & $87.1 \pm 17.3$ & $87.5 \pm 18.0$ & $86.9 \pm 23.0$ & $86.3 \pm 18.7$ & $87.8 \pm 18.4$ & $84.5 \pm 20.5$ \\
DLCO (\%) & $60.0 \pm 16.4$ & $60.2 \pm 16.5$ & $55.8 \pm 17.9$ & $58.5 \pm 14.3$ & $56.0 \pm 17.0$ & $57.5 \pm 5.0$ \\
\hline
\end{tabular}

Data presented as mean \pm standard deviation of 5 silicotic patients

$F E V_{1}$ Forced expiratory volume in $1 \mathrm{~s}$, FCV Forced vital capacity, TLC Total lung capacity,

$T L C$ Total lung capacity, DLCO Diffusing capacity of the lung for carbon monoxide

difference was observed at days 30 and 180 in the left lung (Fig. 4).

\section{Discussion}

The present study evaluated the safety of autologous BMDMC administration through bronchoscopy in patients with silicosis over a period of 360 days. To the best of our knowledge, this was the first study to evaluate the safety of autologous BMDMCs in patients with silicosis. The procedure was well tolerated and no adverse events were observed in the follow-up period. Even though no significant changes were reported in lung function and quality of life, autologous BMDMC transplantation seems to have led to an early increase in perfusion at the base of both lungs, which remained increased for the duration of the follow-up.

Recent studies have investigated the impact of either autologous BMDMCs or mesenchymal stem cells (MSCs) on lung diseases [13-16]. Both cells present particular advantages: BMDMCs can be used in autologous transplantation

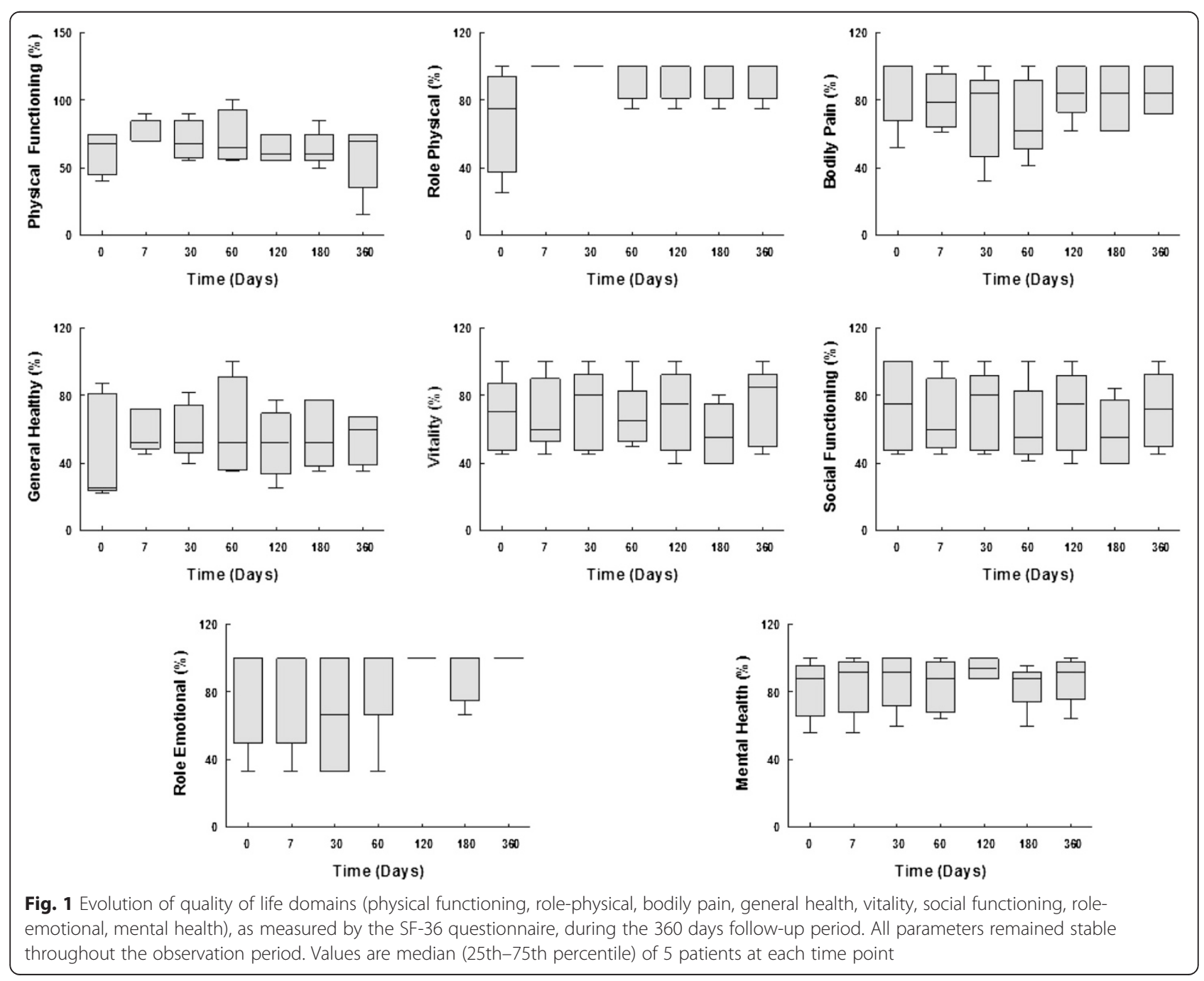




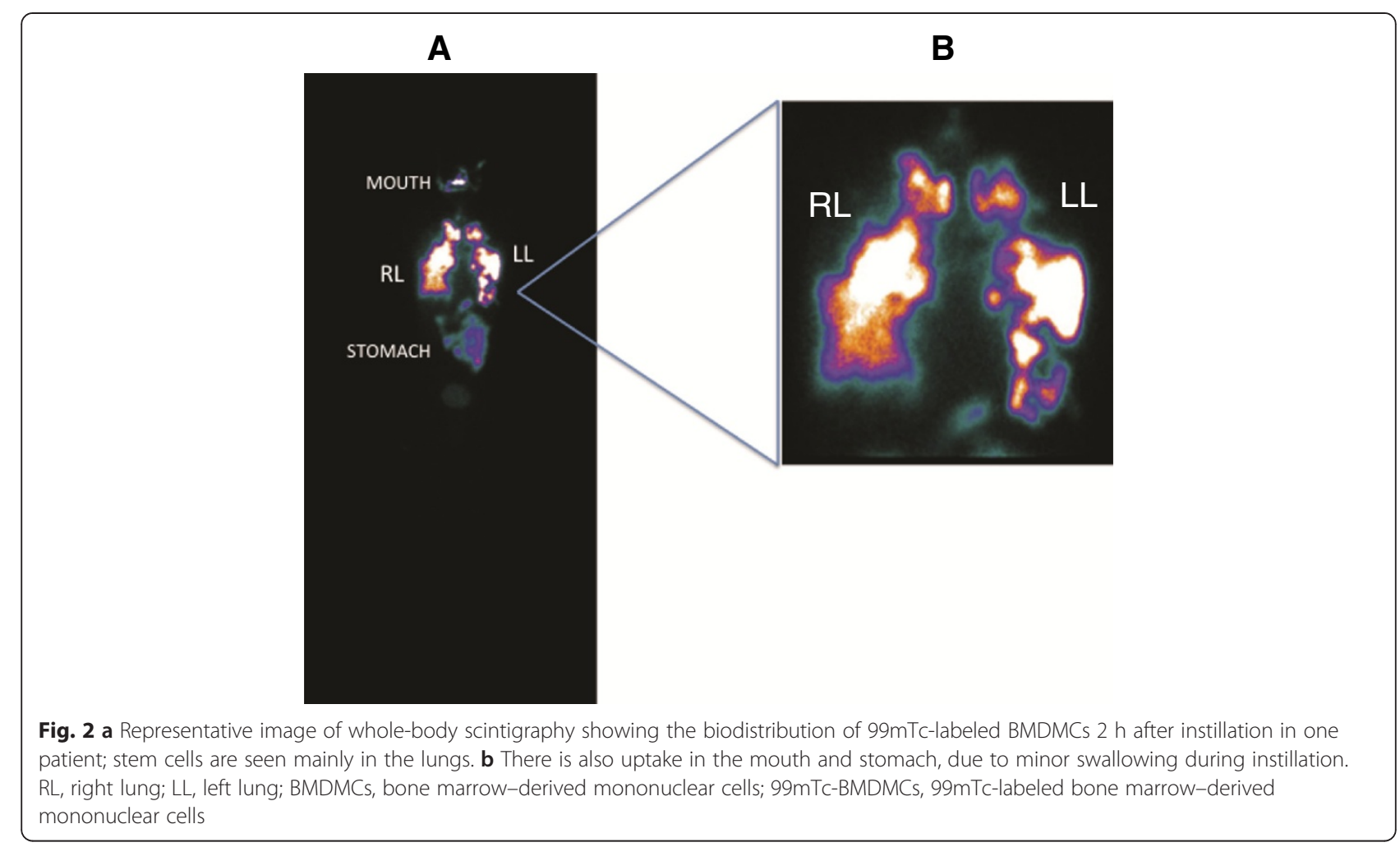

on the same day of harvesting, avoiding common complications such as graft-versus-host disease, whereas MSCs have multilineage differentiation potential and immuneprivileged features that enable allogenic use. So far, clinical studies have demonstrated the safety of systemic BMDMC/MSC infusion in lung diseases, with no early or late adverse effects reported [13]. Intravenous infusion is often used in preclinical and clinical studies for the delivery of various cell types, since this route of administration provides broader biodistribution and is easy to perform [17]. However, the administration of BMDMCs through bronchoscopy into different areas of the lungs may result in a greater number of cells at the site of injury $[18,19]$. We administered a fixed amount of BMDMCs $\left(2 \times 10^{7}\right)$, independent of body weight, based on preclinical and clinical studies on different diseases $[10,11,20]$. To evaluate the early distribution of the injected cells into the lungs, cells were labelled with $99 \mathrm{mTc}$ on the basis of previously published protocols [21, 22]. In vivo imaging and quantification of stem cells is an essential tool for stem cell tracking, although it has inherent limitations. For instance, regardless of which technique is used, cell labeling may cause cellular damage due to the labeling chemicals, and should be carefully

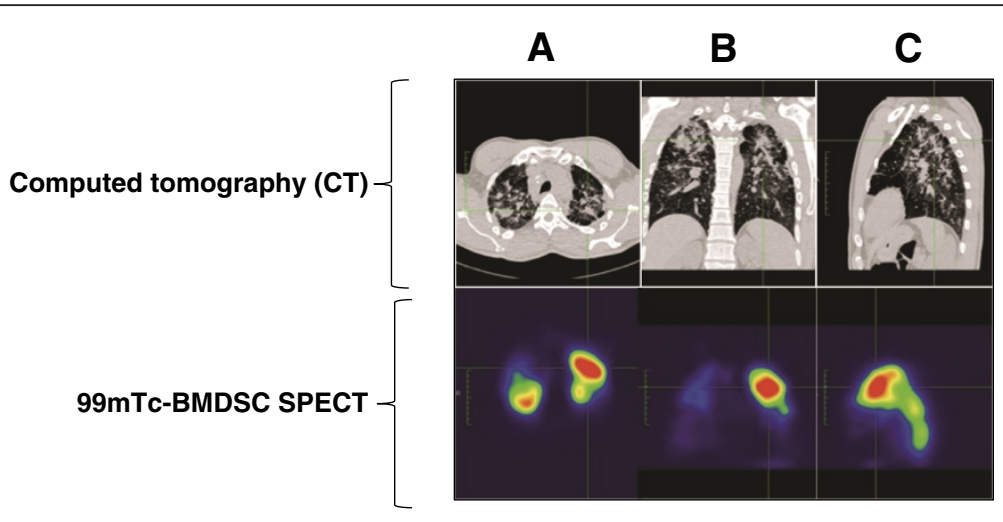

Fig. 3 Representative image of CT and 99mTc-BMDSC SPECT showing correspondence of a left lung lesion (green triangular area). CT, computed tomography; 99mTc-BMDSC, 99mTc-labeled bone marrow-derived mononuclear cells; SPECT, single-photon emission computed tomography 


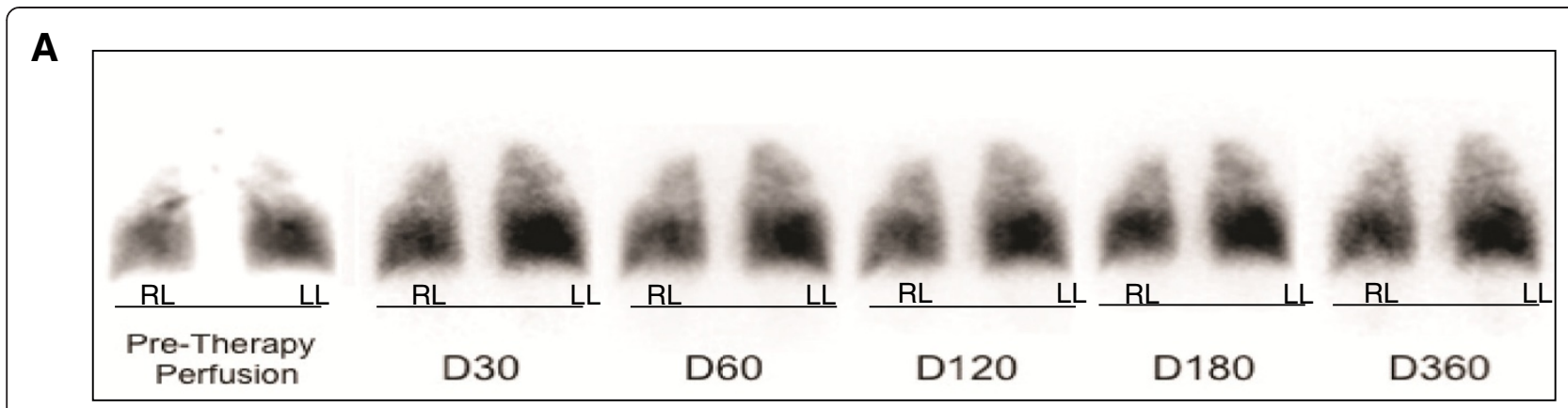

B

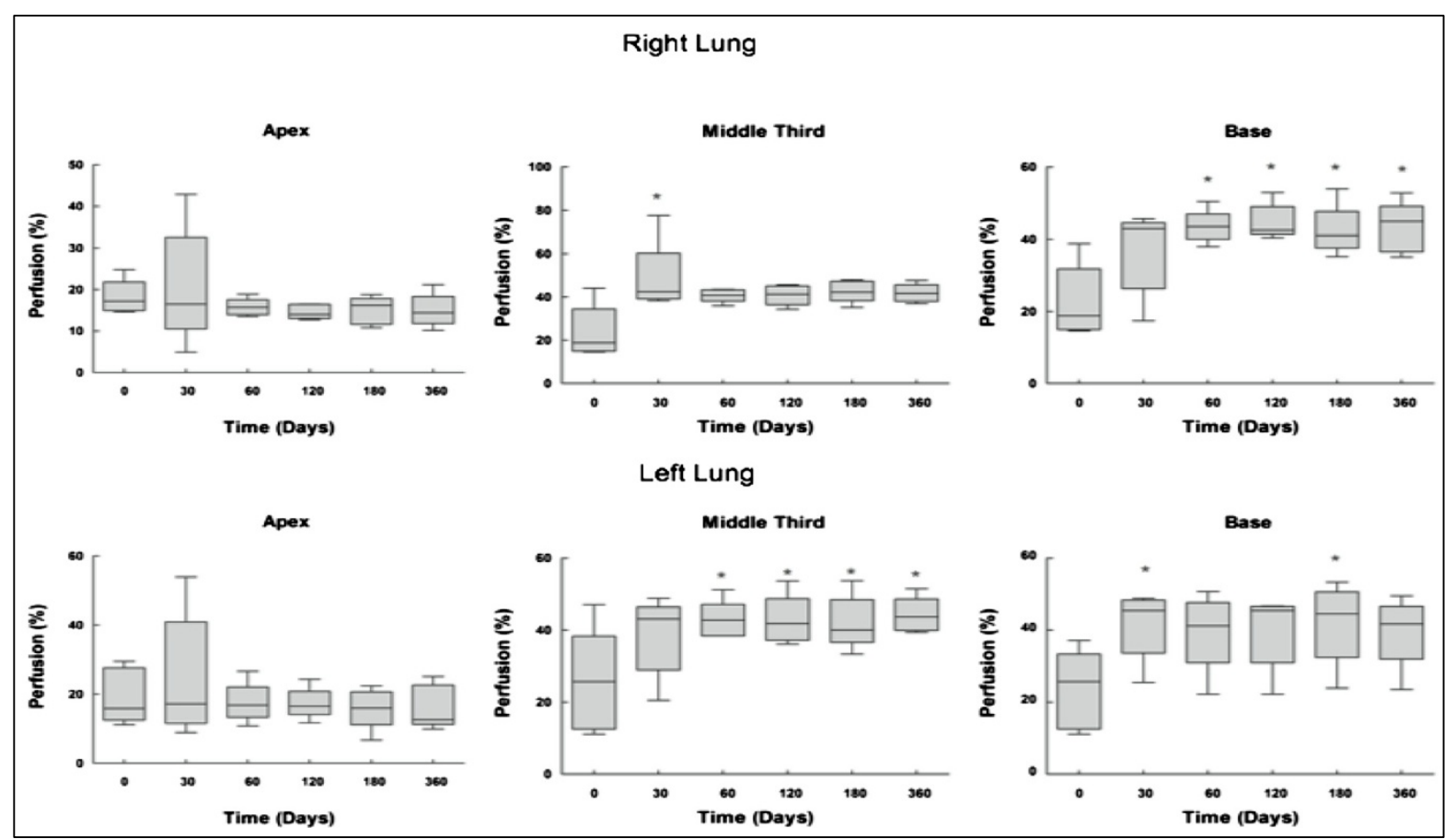

Fig. 4 a 99mTc-macroaggregated albumin perfusion scintigraphy sequences from before cell therapy until 360 days after cell therapy, showing normal uptake at the right base and decreased uptake at both apexes. Improvement in the left base can be seen from day 120 to day 360. b Values are median (25th-75th percentile) of 5 patients at each time point. Statistical analysis of lung perfusion, showing significant differences mainly in the base of the right lungs from day 30 to day 360 as compared with baseline. $R L$, right lung; $L L$, left lung

controlled. Due to the short half-life of $99 \mathrm{mTc}$ (approximately $6 \mathrm{~h}$ ), we cannot rule out that the amount of cells in the lungs may increase at later time points. Other radiopharmaceutical compounds such as indium-111 oxine would allow monitoring for up to $96 \mathrm{~h}$, but have disadvantages, such as the interval of 18-24 h between infusion and imaging that is usually necessary, suboptimal photon energy, and a higher radiation burden for the cells and for the patient [23]. We also used 99mTc-MAA perfusion scintigraphy to follow the likely pattern of distribution of the cells for up to 360 days after infusion.

No adverse events or deaths occurred among the patients treated with BMDMCs. Clinical, functional and radiological parameters were evaluated at 1-year follow-up. The clinical features of this group were stable throughout the follow-up period and no clinical signs or symptoms of bronchitis or pneumonia were observed after BMDMC administration. Even though a 1-year period is not long enough to allow definitive conclusions, it is well known that lung function deteriorates more quickly in patients with silicosis depending on continuation of exposure to silica dust, age and grade of lung lesions [23-25]. The volunteers in our study were relatively young with moderate lung lesions, and exhibited clear stabilization of lung function, which could be attributable to the intervention. This hypothesis would be more clearly demonstrated if a control group with similar characteristics was added to the study. With regard to the quality of life questionnaires, no changes were seen after 360 days of follow-up. An early increase in perfusion at the base of both lungs 
was observed and sustained after BMDMC administration. Based on CT scan analysis, fibrosis was not prominent in the apex of the lung, but distributed across different lung segments. Therefore, the increased perfusion observed in both lung bases was likely not associated with a predominance of fibrosis in any specific segment of the lung. In line with this observation and based on our preclinical data showing that BMDMCs reduce fibrosis in a mouse model of silicosis, we may hypothesize that these cells mitigated progression of fibrosis through paracrine effects.

Since this is a safety study, analysis was only observational, and further larger-scale trials are necessary to fully examine the efficacy of BMDMCs in patients with silicosis.

Experimental studies have demonstrated the efficacy of systemic and intratracheal administration of BMDMCs in a murine model of silicosis $[6-8,26]$ that resembles human silicosis. BMDMC therapy (intratracheally or intravenously administered) reduced both lung inflammation and remodeling, thus improving lung mechanics, through paracrine signaling $[6-8,26]$. Conversely, in the present study, no significant changes in lung function or quality of life indicators were observed over 360 days of analysis. The fact that the clinical result did not reflect the experimental data may be associated with differences in the course of the disease between animal models and humans, the number of cells administered, and the timing of analysis.

Our pilot study was limited by its small sample size; however, it was the first investigation to evaluate stem-cell therapy in silicotic patients. Further studies should be performed in a greater number of patients, with the addition of a control group, and in patients with mild and severe silicosis. Clinical trials evaluating the effects of MSC therapy in idiopathic lung fibrosis (ILF) have been published $[15,16]$. However, this was the first study that analyzed the safety of autologous BMDMCs in patients with silicosis and, in contrast with the studies, no adverse events were observed. In this line, two clinical trials involving the endobronchial or systemic delivery of autologous adipose tissue-derived [15] or placenta-derived mesenchymal stem cells [16] demonstrated that these treatments are not safe in patients with IPF. In the first clinical trial, transient fever (50\% of patients), cough, dyspnea, and increased heart rate (14\% of patients) were observed following each endobronchial cell administration [15], and one patient experienced a change in absolute FVC of more than $10 \%$ at 6 months, suggesting disease progression. A second phase $1 \mathrm{~b}$ study on the use of exogenous placenta-derived MSCs in patients with IPF also observed adverse effects after therapy [16].

\section{Future perspectives}

Clinical studies are required to evaluate the safety of different doses and treatment intervals of BMDMC administration and to analyze the efficacy of this approach, including pulmonary and systemic hemodynamics, lung function, hospitalizations, infections, and death. The use of a single infusion or repeated infusions also needs to be addressed, even though multiple infusions could lead to right heart overload (and pulmonary hypertension) [27]. Most patients with silicosis are not diagnosed in the early stages of the disease, but identification of these patients should be considered for a clinical trial of cell therapy. Clinical trials should include patients with different degrees of lung function impairment due to silicosis.

\section{Conclusion}

Based on this preliminary study, the administration of BMDMCs through bronchoscopy appears to be safe. Certainly, further clinical investigation of BMDMCs or even other cell types in patients with silicosis is warranted.

\section{Competing interests}

The authors declare that they have no competing interests.

\section{Authors' contributions}

MMM conceived of the study, participated in its design, coordinated its conduction, and helped draft the manuscript. SALS carried out the imaging analysis. $L P L, M A L$, and $A S$ participated in the evaluation of quality of life domains and in the instillation procedure. LV and THKB prepared BMMCs for instillation. BG assisted in imaging analysis. MLP helped draft the manuscript and assisted in statistical analysis. AJA and APA participated in the quality of life evaluation. RCG contributed to the study design. PRMR conceived of the study, participated in its design, and assisted in statistical analysis and manuscript drafting. LMBF conceived of the study and coordinated its conduction. JPLS conceived of the study, participated in its design and coordination, and helped draft the manuscript. All authors read and approved the final manuscript.

\section{Acknowledgements}

The authors would like to express their gratitude to Mr. Andre Benedito da Silva, Miss Priscila Carneiro and Mrs. Ana Lucia Neves da Silva for their skillful technical assistance, and Moira Elizabeth Schöttler and Mr. Filippe Vasconcellos for their assistance in editing the manuscript.

\section{Supported by}

The Centers of Excellence Program (PRONEX-FAPERJ), the Brazilian Council for Scientific and Technological Development (CNPq), the Carlos Chagas Filho Rio de Janeiro State Research Foundation (FAPERJ), and the Coordination for the Improvement of Higher Level Personnel (CAPES).

\section{Author details}

${ }^{1}$ Laboratory of Cellular and Molecular Physiology, Institute of Biophysics Carlos Chagas Filho, da Saude Science Center, Federal University of Rio de Janeiro, Ilha do Fundão, 21941-902 Rio de Janeiro, RJ, Brazil. ${ }^{2}$ Nuclear Medicine Service, Clementino Fraga Filho University Hospital, Federal University of Rio de Janeiro, Rio de Janeiro, Brazil. ${ }^{3}$ Institute of Thoracic Medicine, Clementino Fraga Filho University Hospital, Federal University of Rio de Janeiro, Rio de Janeiro, Brazil. ${ }^{4}$ Laboratory of Cellular and Molecular Cardiology, Institute of Biophysics Carlos Chagas Filho, Federal University of Rio de Janeiro, Rio de Janeiro, Brazil. ${ }^{5}$ Laboratory of Pulmonary Investigation, Institute of Biophysics Carlos Chagas Filho, Federal University of Rio de Janeiro, Rio de Janeiro, Brazil.

Received: 13 March 2015 Accepted: 28 May 2015 Published online: 11 June 2015

\section{References}

1. Greenberg MI, Waksman J, Curtis J. Silicosis: a review. Dis Mon. 2007;53(8):394-416. 
2. Huaux F. New developments in the understanding of immunology in silicosis. Curr Opin Allergy Clin Immunol. 2007;7(2):168-73.

3. Leung CC, Yu IT, Chen W. Silicosis. Lancet. 2012;379(9830):2008-18.

4. Weiss DJ. Concise review: current status of stem cell and regenerative medicine in lung biology and diseases. Stem Cells. 2014;32(1):16-25.

5. Silva JD, Paredes BD, Araújo IM, Lopes-Pacheco M, Oliveira MV, Suhett GD, Faccioli LA, Assis E, Castro-Faria-Neto HC, Goldenberg RC, Capelozzi VL, Morales MM, Pelosi P, Xisto DG, Rocco PR. Effects of bone marrow-derived mononuclear cells from healthy or acute respiratory distress syndrome donors on recipient lung-injured mice. Crit Care Med. 2014;42(7):e510-24.

6. Maron-Gutierrez T, Castiglione RC, Xisto DG, Oliveira MG, Cruz FF, Peçanha R, Carreira-Junior H, Ornellas DS, Moraes MO, Takiya CM, Rocco PR, Morales MM. Bone marrow-derived mononuclear cell therapy attenuates silica-induced lung fibrosis. Eur Respir J. 2011;37(5):1217-25.

7. Lopes-Pacheco M, Xisto DG, Ornellas FM, Antunes MA, Abreu SC, Rocco PR, Takiya CM, Morales MM. Repeated administration of bone marrow-derived cells prevents disease progression in experimental silicosis. Cell Physiol Biochem. 2013;32(6):1681-94.

8. Lopes-Pacheco M, Ventura TG, de Oliveira HD, Monção-Ribeiro LC, Gutfilen B, de Souza AS, Rocco PR, Borojevic R, Morales MM, Takiya CM. Infusion of bone marrow mononuclear cells reduces lung fibrosis but not inflammation in the late stages of murine silicosis. PLoS One. 2014;9(10):e109982.

9. Terra-Filho M, Santos UP. Silicose. J Bras Pneumol. 2006;32 Suppl 2:S59-65.

10. Barbosa da Fonseca LM, Battistella V, de Freitas GR, Gutfilen B, Dos Santos Goldenberg RC, Maiolino A, Wajnberg E, Rosado de Castro PH, MendezOtero R, Andre C. Early tissue distribution of bone marrow mononuclear cells after intra-arterial delivery in a patient with chronic stroke. Circulation. 2009;120(6):539-41.

11. Barbosa da Fonseca LM, Gutfilen B, Rosado de Castro PH, Battistella V, Goldenberg RC, Kasai-Brunswick T, Chagas CL, Wajnberg E, Maiolino A Salles Xavier S, Andre C, Mendez-Otero R, de Freitas GR. Migration and homing of bone-marrow mononuclear cells in chronic ischemic stroke after intra-arterial injection. Exp Neurol. 2010;221(1):122-8.

12. Ohno $Y$, Hatabu H, Higashino T, Takenaka D, Watanabe $H$, Nishimura $Y$, Yoshimura M, Sugimura K. Dynamic perfusion MRI versus perfusion scintigraphy: prediction of postoperative lung function in patients with lung cancer. AJR Am J Roentgenol. 2004;182(1):73-8.

13. Ribeiro-Paes JT, Bilaqui A, Greco O, Ruiz MA, Marcelino MY, Stessuk T, de Faria CA, Lago MR. Unicentric study of cell therapy in chronic obstructive pulmonary disease/pulmonary emphysema. Int J Chron Obstruct Pulmon Dis. 2011;6:63-71.

14. Weiss DJ, Casaburi R, Flannery R, LeRoux-Williams M, Tashkin DP. A placebocontrolled randomized trial of mesenchymal stem cells in COPD. Chest. 2013;143(6):1590-8.

15. Tzouvelekis A, Paspaliaris V, Koliakos G, Ntolios P, Bouros E, Okionomou A, Zissimopoulos A, Boussios N, Gritzalis D, Antoniadis A, Froudarakis M, Kolios G, Bouros D. A prospective, non-randomized, no placebo-controlled, phase Ib clinical trial to study the safety of the adipose derived stromal cellsstromal vascular fraction in idiopathic pulmonary fibrosis. J Transl Med. 2013;11:171.

16. Chambers DC, Enever D, Ilic N, Sparks L, Whitelaw K, Ayres J, Yerkovich ST, Khalil D, Atkinson KM, Hopkins PM. A phase 1b study of placenta-derived mesenchymal stromal cells in patients with idiopathic pulmonary fibrosis. Respirology. 2014;19:1013-8.

17. Hicks A, Jolkkonen J. Challenges and possibilities of intravascular cell therapy in stroke. Acta Neurobiol Exp (Wars). 2009;69(1):1-11.

18. Schrepfer S, Deuse T, Reichenspurner H, Fischbein MP, Robbins RC, Pelletier MP. Stem cell transplantation: the lung barrier. Transplant Proc. 2007;39(2):573-6.

19. Bonios M, Terrovitis J, Chang CY, Engles JM, Higuchi T, Lautamäki R, Yu J, Fox J, Pomper M, Wahl RL, Tsui BM, O'Rourke B, Bengel FM, Marbán E, Abraham MR. Myocardial substrate and route of administration determine acute cardiac retention and lung bio-distribution of cardiosphere-derived cells. J Nucl Cardiol. 2011;18(3):443-50.

20. Vasconcelos-dos-Santos A, Rosado-de-Castro PH, Lopesde Souza SA, da Costa Silva J, Ramos AB, Rodriguez de Freitas G, Barbosa da Fonseca LM, Gutfilen B, Mendez-Otero R. Intravenous and intra-arterial administration of bone marrow mononuclear cells after focal cerebral ischemia: is there a difference in biodistribution and efficacy? Stem Cell Res. 2012;9(1):1-8.

21. Barbosa da Fonseca LM, Xavier SS, Rosado de Castro PH, Lima RS, Gutfilen B, Goldenberg RC, Maiolino A, Chagas CL, Pedrosa RC, Campos de Carvalho AC. Biodistribution of bone marrow mononuclear cells in chronic chagasic cardiomyopathy after intracoronary injection. Int J Cardiol. 2011;149(3):310-4.

22. Rosado-de-Castro PH, Schmidt F d R, Battistella V, Lopes de Souza SA, Gutfilen B, Goldenberg RC, Kasai-Brunswick TH, Vairo L, Silva RM, Wajnberg E, Alvarenga Americano do Brasil PE, Gasparetto EL, Maiolino A, Alves-Leon SV, Andre C, Mendez-Otero R, Rodriguez de Freitas G, Barbosa da Fonseca LM. Biodistribution of bone marrow mononuclear cells after intra-arterial or intravenous transplantation in subacute stroke patients. Regen Med. 2013;8(2):145-55.

23. Banerjee SR, Maresca KP, Francesconi L, Valliant J, Babich JW, Zubieta J. New directions in the coordination chemistry of $99 \mathrm{mTC}$ : a reflection on technetium core structures and a strategy for new chelate design. Nucl Med Biol. 2005;32(1):1-20.

24. Cowie RL. The influence of silicosis on deteriorating lung function in gold miners. Chest. 1998;113(2):340-3.

25. Ochmann U, Kotschy-Lang N, Raab W, Kellberger J, Nowak D, Jörres RA. Long-term efficacy of pulmonary rehabilitation in patients with occupational respiratory diseases. Respiration. 2012;84(5):396-405.

26. Lassance RM, Prota LF, Maron-Gutierrez T, Garcia CS, Abreus SC, Pássaro CP, Xisto DG, Castiglione RC, Carreira H Jr, Ornellas DS, Santana MC, Souza SA, Gutfilen B, Fonseca LM, Rocco PR, Morales MM. Intratracheal instillation of boné marrow-derived cell in na experimental modelo f silicosis. Respir Physiol Neurobiol. 2009;169(3):227-33.

27. Glassberg MK, Hare JM, Toonkell RL, Mathay MA. Reply: idiopathic pulmonary fibrosis: a degenerative disease requiring a regenerative approach. Am J Resp Crit Care Med. 2013;188(2):253-4.

\section{Submit your next manuscript to BioMed Central and take full advantage of:}

- Convenient online submission

- Thorough peer review

- No space constraints or color figure charges

- Immediate publication on acceptance

- Inclusion in PubMed, CAS, Scopus and Google Scholar

- Research which is freely available for redistribution 